\title{
O CORPO DA PALAVRA OU A PALAVRA DO CORPO A escrita como criação
}

\author{
EL CUERPO DE LA PALABRA O LA PALABRA DEL CUERPO \\ La escritura como creación
}

\section{THE WORDS IN THE BODY AND THE BODY IN WORDS Writing as creation}

\author{
Ana Cristina Colla ${ }^{1}$
}

\begin{abstract}
RESUMO
Essa escrita em deriva circula por angústias, desejos, descobertas, palpites, certezas, intuições, em torno do desafio presente na pesquisa artística acadêmica, mais especificamente das artes presenciais, sobre a experimentação de modos de narrar que tenham no próprio corpo seu principal vetor de criação. Quais as narrativas possíveis que possam dialogar com os diferentes territórios e tempos (paralelos, cruzados, sobrepostos) por onde circulam a criação? Entendendo a narratividade como uma posição política que tomamos em relação ao mundo e a nós mesmos.
\end{abstract}

PALAVRAS-CHAVE: experiência, modos de escrita, narratividade

\section{RESUMEN}

Esta escritura en deriva circula por angustias, deseos, descubrimientos, conjeturas, certezas, intuiciones, en torno al desafío presente en la investigación artística académica, más específicamente de las artes presenciales, sobre la experimentación de modos de narrar que en el propio cuerpo su principal vector de creación. ¿Cuáles son las narrativas posibles que puedan dialogar con los diferentes territorios y tiempos (paralelos, cruzados, sobrepuestos) por donde circulan la creación? Entendiendo la narratividad como una posición política que tomamos en relación al mundo ya nosotros mismos.

PALABRAS CLAVE: modos de escritura, experiencia, narratividad

\begin{abstract}
This drifting writing floats around anguish, desires, discoveries, hunches, certainties, intuitions on the current challenge in the academic artistic research, more specifically the on-site arts, in which has the experimentation of narrating ways as the main vector of creation in their bodies. What possible narratives can dialogue with the different territories and times (parallel, cross, overlapping) through which the creation circulates? Understanding narrativity as a political position we hold in relation to the world and ourselves.
\end{abstract}

KEYWORDS: modes of writing, experience, narrativity

1 Atriz, pesquisadora do LUME Teatro: Núcleo Interdisciplinar de Pesquisas Teatrais e Professora Titular do Programa de Pós-Graduação em Artes da Cena da Universidade Estadual de Campinas - UNICAMP. 
Essa escrita em deriva circula por angústias, desejos, descobertas, palpites, certezas, intuições, em torno do desafio presente na pesquisa artística acadêmica, mais especificamente das artes presenciais, sobre a experimentação de modos de narrar que tenham no próprio corpo seu principal vetor de criação. Quais as narrativas possíveis que possam dialogar com os diferentes territórios e tempos (paralelos, cruzados, sobrepostos) por onde circulam a criação? Entendendo a narratividade como uma posição política que tomamos em relação ao mundo e a nós mesmos.

Essa escrita na verdade é uma fala. Foi escrita para ser falada e ouvida. $^{2}$

Enquanto fala vem acompanhada de um corpo que propõe ações, camadas que compõem com as palavras. Sons, gestos, olhares, respiros. Enquanto palavra falada ou palavra corpo ela encontra o outro, que ouve, olha, respira. Esse encontro, aqui no papel, precisa ser criado, imaginado, pra se tornar real. Pra nos encontrarmos.

Estou à sua frente, em pé. Tenho uma bolsa de feira verde ao meu lado. Dentro, livros.

Meu nome é Ana Cristina, sou filha de Ana, neta de Maria. Era pra me chamar Ana Maria mas a vó disse que as Marias sofriam demais, aí me nomearam de Ana Cristina, de Cristo. Que não sofre, né? Sou atriz do Lume Teatro há 24 anos e pela urgência desse trabalho de atriz é que comecei a escrever.

Ligo um metrônomo. Ouvimos ao fundo TacTacTacTac

O tempo se faz corpo presente. As palavras saem em fluxo rápido, impulsionadas pelo som ininterrupto ao fundo.

\section{TacTacTacTac}

Agora leio as palavras em folhas de papel sulfite.

Pensei em muitas maneiras de estar aqui hoje, queria algo performático, que pudesse impressionar e me tirar de uma cadeira, detrás

\footnotetext{
${ }^{2}$ Os pensamentos aqui presentes foram elaborados e apresentados na mesa de discussão "O Corpo da Palavra ou a Palavra do Corpo: a escrita como criação" durante o VII Simpósio Internacional Reflexões Cênicas Contemporâneas, em 23 de fevereiro de 2018. A apresentação performada pode ser conferida no link:

https://www.youtube.com/watch?v=FptqY9eovWk\&t=5806s
} 
das mesas, local das falas importantes. Não que eu desmereça esse lugar, mas ele me apavora. Penso melhor em pé, com os pés fincados no chão e certo desassossego no corpo. Aí pensei que poderia mascarar esse medo fazendo algo bem criativo. Busquei uma ideia genial, tive várias, anotei possibilidades no meu caderno rosa, o caderno das ideias especiais e quando reli dias depois essas mesmas ideias me pareceram vagas e nada geniais. Em uma delas eu estaria NUA, com palavras escritas no corpo com tinta guache preta, já fiz isso num espetáculo, chamava "Você" (que falava de mim mesma ou do espaço que me separa de você), depois iria jogar tinta no corpo e rolar por um imenso papel kraft estendido no chão, imprimindo as cores e as palavras no papel. Já fiz isso também quando era estudante na graduação em Artes Cênicas na Unicamp. Peguei uma tinta látex azul do depósito e me besuntei com ela. Foi lindo e me rendeu vários dias com a pele vermelha empipocada. Adoro ficar pelada, então quase todas as ideias envolviam a pele nua. Adoro PELE, essa parte imensa do meu corpo que me delimita e não permite que eu jorre pra fora, ao mesmo tempo que arrepia quando alguém me toca, rasga, é cheia de marcas e se enruga mais a cada dia.

Pensei também em espalhar meus diários de trabalho.

Cadernos multicoloridos começam a ser espalhados pelo chão.

Eu adoro CADERNOS de diferentes cores e tamanhos, rascunhos de ideias, papéis, um caos em letras que me ajudam a traçar os caminhos por onde me perdi. Gosto de me PERDER, ajuda a me encontrar.

Pensei em trazer LIVROS.

Maria Gabriela Llansol, Gonçalo Tavares, Bartolomeu de Queirós, Kuniichi Uno, entre outros, marcam presença ao lado dos diários, o chão se torna povoado de palavras.

Fiquei com medo de parecer exibida como os colegas da graduação quando vinham para os seminários e traziam pilhas de livros pra deixar em cima da mesa, tentando impressionar e só muito depois percebi que eram livros vazios, nunca lidos por eles. Livros tristes que compõem, muitas 
vezes, as vastas bibliografias de nossos artigos atestando nossa sabedoria. Mas como os livros me salvam a cada dia, me apresentando mundos que eu nem suspeitava, eu os trouxe mesmo assim, queria tê-los ao meu lado. Pensei em usar Power Pointpra deixar essa fala mais presente, evitando que as palavras escapassem pelos ouvidos, na verdade a palavra primeiro que me veio foi slide, projetor, aí vi que era coisa de velha. Até escrevi pra uma amiga perguntando sobre uma ferramenta nova, "Prezi" ela me ensinou, era o nome de um aplicativo mais moderno e interativo que me permitiria colocar imagens, cores, pra tentar mostrar o por detrás ou além das palavras. Essa era minha angústia: nomear o entre, o não dito, aquilo que não é palpável. O "Prezi” acabou não me ajudando, tentei, juro que tentei, mas vi que levaria séculos pra eu conseguir aprender e não daria tempo.

\section{TacTacTacTac}

Aí imprimi o texto nessas folhas, me sentindo um pouco ridícula, mas pensando que elas me dariam segurança e seria uma alternativa pra sair detrás da mesa. E eu me propus a falar sobre escrita, sobre a palavra e eu sou atriz, e eu quase nem publico os textos que escrevo, "o que eu tô fazendo aqui?!". Às vezes me sinto uma IMPOSTORA. O Professor Fernando Villar me fez essa pergunta na banca de defesa da minha tese de doutorado: "quando é que você vai parar de se sentir uma impostora dentro da academia?". Sei lá, acho que é síndrome de quem veio da escola pública e foi educada por pais semianalfabetos. A voz embarga. As palavras tremem. Sua benção, meu pai. Mesmo tendo sido meu PAI que me ensinou a amar os livros e as palavras. Ele tinha catarata e só podia ler durante o dia, quando a luz era mais forte, sentado na varanda comigo enganchada no colo dele. Ali, dia a dia, ele me ensinou como as palavras são criadoras de mundos.

Mas depois pensei que a proposta era falar sobre o corpo da escrita e eu sou um corpo que escreve, então fiquei mais confortável, porque eu escrevo, escrevo muito, escrevo tudo que vejo, sinto, descubro, tudo que leio, meus livros tem garranchos por todo lado, fico discutindo com o autor como se ele pudesse me ouvir, converso com ele, brigo, me ilumino. Escrevo pouco 
porque não gosto de escrever sob encomenda, detesto palavra morta, vazia, gasta. E pra ela brotar fresquinha, sangrando, leva tempo, precisa de cuidado, muito mimo, paixão e trabalho braçal.

Voltando para o começo. Meu nome é Ana Cristina, nasci miúda, míope me tornei quando comecei a crescer. Ser atriz nunca foi sonho, fui sendo. Talvez pela vocação de ser casulo.

Assim me apresento porque gosto de fincar RAÍZES. Mostrar filiação. Descobri que só sei falar do que é meu. Daquilo que me atravessa, fura, vaza. Do meu quintal lanço o olhar para o mundo. Da minha janela vejo... assim nomeei meus primeiros escritos. Tá aqui nesse caderninho laranja. Quem olha, olha de algum lugar, e esse lugar, muitas vezes, determina o olhar. “... entendi que o mundo da escrita não dependia de Londres nem de Milão, mas girava em torno da mão que escrevia, no lugar que escrevia: aqui está você - aqui é o centro do universo" (OZ, 2005, p.557).

Risco com giz um pequeno círculo em torno de mim mesma, repetindo as palavras: “aqui está você, aqui é o centro do universo".

Aqui, hoje, eu falo como ATRIZ. Uma atriz que se propôs a investigar a cena e a narrarprocessos criativos. Escrevo sobre o vivido, depois me envergonho e me calo em seguida. Sem-vergonha, esqueço da vergonha e escrevo de novo, sabendo que ela logo virá. Acho graça nesse medo de dizer e me digo.

Meus primeiros escritos durante o mestrado tinham cara de relatório científico para a Fapesp, limpinhos, cheirosinhos e sem vida. "A pesquisadora Ana Cristina Colla...”. Tive a sorte de ter como orientadora, durante esse período da minha formação acadêmica, a Profa. Suzi Frankl Sperber, que vem da literatura. Assim que apresentei a ela meus primeiros textos - o meu projeto, naquele momento, era uma reflexão sobre os meus primeiros 10 anos como atriz pesquisadora no Lume Teatro - ela puxou meu tapete com a seguinte provocação: "o texto está bom para ser um relatório para a Fapesp, está claro, bem redigido, mas poderia ter sido escrito por qualquer um dos atores do Lume. Cadê você?".

Cadê eu? 
A pergunta ficou ecoando...

\section{TacTacTacTac}

Depois dessa provocação, entrei em crise, sofri, me flagelei! E saí pra briga. Cadê eu?

E nessa época me brotou uma pergunta que me guia até hoje: no território da escrita, qual é o verbo do ator?

Não o do diretor, do teórico, do crítico teatral, mas do ator, no meu caso da atriz, mulher, mãe, filha, camadas todas entranhadas na minha escrita. Nós atrizes/atores, quando entramos numa sala de trabalho nos propomos a construir uma EXPERIÊNCIA, seja sozinha/o ou acompanhada/o. E nosso espaço de trabalho pode ser a rua, a chuva, a mata, a noite, o zoológico. Investigamos diferentes pontos de partida pra que essa intensificação de vida aconteça: exercícios físicos diversos, música, silêncio, imagens poéticas, textos, objetos, solidão, o outro. E são inúmeras as vezes que não encontramos nada de tanto procurar e por vezes é justamente desse NADA que brota algo precioso. Lidamos todos os dias com um estado de suspensão de nós mesmos e de nossas expectativas, o que nos obriga a lidar com o tempo e com a percepção de maneira diversa da maioria das pessoas. Quatro horas entre paredes podem significar uma viagem de anos. Quantas experiências intensas vivemos que não parecem ter sentido ou seriam até mesmo absurdas ou ridículas em qualquer outro contexto? Ficar cinquenta minutos se equilibrando em uma perna só. Alguém já ficou? Eu já fiquei. Ou levar trinta minutos para sentar? Eu já. Tadashi Endo, bailarino de butoh, que trabalha com a dilatação e com a suspensão do tempo, fez essa proposição aos atores do Lume. E aí, sou melhor atriz por isso? Claro que não. Não é me equilibrar numa perna só ou me sentar muito lento que é o importante, mas sim a proposição para a realização dessa experiência. E os extremos que essa proposição me provoca enquanto experiência intensa.

A primeira proposição é a SUSPENSÃO DO TEMPO externo.

\section{Paro o metrônomo. Alívio. Silêncio.}

E a instalação de um tempo outro, dilatado, a ser descoberto, que me exige esforço para sua manutenção. Aqui, paro pra pensar em ação, para 
escutar o movimento, rompo com os automatismos, cultivo uma atenção mais fina e me delicio com a lentidão. Redescubro minha respiração, o limite de cada feixe muscular que sustenta meu corpo e o peso imenso que ele parece possuir agora. Tento esvaziar o pensamento, pensando sem parar "merda, que ideia foi essa?!". "Quanto tempo será que já se passou, será que falta muito?", até que os excessos vão passando, a ansiedade vai dando espaço para uma percepção mais sutil, permeada por imagens múltiplas, sensações, pequenos prazeres.

Como segunda proposição, suspendo o juízo e a vontade, sim, porque, do contrário, me sentiria estúpida por suar em bicas e suportar dores musculares para a execução de uma ação que eu poderia realizar em segundos e quase sem esforço, assim me abro para ser afetada pela experiência a que me propus. E talvez a premissa mais importante para provocar essa vivência seja a construção de um processo investigativo que envolva o risco, a vulnerabilidade, a exposição, o desassossego. Ir além do confortável, conhecido, mastigado.

E como dar voz a esse turbilhão, que escrita esse corpo pede? Que corpo é esse que escreve?

Sendo assim, entendo a escrita vinculada à experiência, aos rastros, às marcas. Entendendo que somos esse território de passagem, essa zona de confluência onde distintas forças nos interpelam, somos o espaço onde as coisas acontecem, o lugar da experiência.

Sueli Rolnik fala sobre MARCAS, "escrever para mim é na maioria das vezes conduzido e exigido pelas marcas: dá pra dizer que são as marcas que escrevem" (ROLNIK, 1993, p.9). Exigido e conduzido por elas, marcas que pedem e exigem passagem, nos guiando pelos caminhos. E continua,

o que vem primeiro é a capacidade de se deixar violentar pelas marcas, o que nada tem de subjetivo ou individual pois ao contrário, as marcas são os estados vividos em nosso corpo no encontro com outros corpos, a diferença que nos arranca de nós mesmos e nos torna outro" (ROLNIK, 1993, p.5).

Reparem que ela usa a palavra violentar, "se deixar violentar" como uma capacidade de se deixar afetar, abrir espaço e o que vem nem sempre é suave, deixa marcas, desenha na pele, nos ossos, no olhar. Violência aqui 
como uma força que move, criativa, que desacomoda, e não aquela violência que provoca submissão. E fala sobre marcas como estados vividos no "ENCONTRO", outra palavra importante, encontro com outros corpos que nos desacomodam e nos arrancam de nós mesmos, seja esse outro gente, bicho, planta, pedra. Portanto, o "quintal" de onde lanço o olhar é poroso e relacional.

Faço com as mãos aberturas,pequenas fissuras, no círculo de giz desenhado no chão

E aqui chegamos a um corpo não como sujeito identitário, um euzinho reinante, um eu que fala a partir do próprio umbigo, mas um eu que se define a partir das relações que estabelece, como potência de afetar e ser afetado. E não como afirmação de um sujeito. Estamos falando de um corpo que é nosso campo de batalha, que aceita contornos, mas não se submete a formas definidas, "aberto ao tempo infinito não humano, aberto aos animais, às plantas, aos minerais, às moléculas" (UNO, 2012, p.52). Um corpo que é, ao mesmo tempo, sujeito e objeto, o possuímos e somos possuídos por ele. Um corpo que não se submete ao nosso pensamento, que nos trai, provoca, surpreende. Corpo fluído, em constante atualização, "composto por partículas infinitas que variam sem cessar" (UNO, 2012, p.55). Um corpo como tempo mais do que como espaço.

Hijikata tem uma expressão: "O que aconteceria se descêssemos no corpo, colocando uma escada até sua profundeza?" (in UNO, 2012, p.56).

Repito: o que aconteceria se descêssemos no corpo, colocando uma escada até sua profundeza?

E a escrita que surge, como organizadora dos pensamentos fruto dessa experiência intensiva, faz parte e é mais um elemento desse plano de consistência. Ela ancora, dá passagem a uma rede de afetos, referências, partes inerentes de um trabalho investigativo comprometido com o rigor. "Falar por afeto, por experimentação, falar em nome próprio, falar no singular" (ROLNIK, 2011, p.40). 
Trago para esta fala a voz contundente de Sara Elton Panamby, destacando um trecho da introdução da sua tese de doutorado, defendida na Universidade Federal do Rio de Janeiro.

Foi no sonho que me vieram as intelectuais pretas me dizer da importância desta fala jorrada. Quando o subalterno pode falar? De que maneiras pode falar? Sobre o que pode falar? Não fale alto, não fale coisas pessoais, não seja violenta, não seja autobiográfica, não se vitimize, fale de coisas universais. Universais, universos plenos de espaços brancos. É de uma tenacidade o que fazemos aqui: utilizando as ferramentas eurocêntricas para destituir a eurocentralidade. Burlando regras, falando em sotaques desconhecidos, cifrando segredos. Subalternos, selvagens... as palavras em nossas mãos são armamentos pesados. Por isso nos enforcaram, queimaram na fogueira, imolaram, deram um tiro na nuca. A subalternidade fala pela língua dos estilhaços, pelas ruínas do que fomos, a memória apartada, os caminhos as rotas encobertas pelas folhas de aço do progresso. Somos fragmentos de histórias que ainda são catadas quando estamos de cócoras. É sobre o corpo de minhas avós então que me deito. Na cova de Ana, Rita e Raimundo, fundo na terra cimentada, exumo seus corpos para me reconhecer. Sento no ombro vivo de José para espiar o que ele enxerga com os olhos puxados de caboclo vermelho, na gagueira de todos os tempos ouvir idiomas que falam outras vozes.

É com, sobre e para esses corpos retirantes que escrevo e não posso começa-lo sem antes assumir a problemática das contradições que colocam este corpo que escreve e se inscreve num jogo de forças. Como um avestruz, escondo minha cabeça na terra e dou a ver o cu (PANAMBY, 2017, p.12).

De onde eu falo? Como eu me nomeio? As palavras com que cada um de nós se nomeia diz imensamente quem somos.

Quantas maneiras temos pra nos definir?

"Prazer, sou a Cris, filha da Ana, neta da Maria, lá de São João da Boa Vista...”

"Boa tarde, eu sou Ana Cristina Colla, atriz do Lume Teatro há vinte e quatro anos, professora do Programa de Pós-Graduação em Artes da Cena, da Unicamp...”

E por aí vai...

Elas podem matar! Podem acariciar, podem torturar, alfinetar e sabemos muito bem como usá-las para cada um desses fins. Mas quando vamos escrever para narrar processos parece que ficamos mudos e meio ingênuos, esquecidos!

Quem eu trago para conversar comigo? Quais são meus PARCEIROS? Que discurso eu quero validar, dar visibilidade? Por que eu não posso colocar para dialogar o Seu Renato Torto e a Maria Gabriela Llansol? Ele, caçador de lobisomem do interior de Goiás - com quem cruzei 
nas ruas de Jaraguá e que depois de uma breve conversa me convidou para visitar sua casa, onde me apresentou histórias desse e de outros mundos (e se faz corpo em meu corpo há 25 anos) -, ela, escritora portuguesa, que conheci pelas palavras impressas no papel, tão vivas e provocativas, me apresentando uma escrita corpo sem impostura. Com o Seu Renato Torto aprendi uma oração de parar sangue.

O corpo se inclina para frente, as pernas se separam dando suporte, o queixo se projeta, os olhos se arregalam, a voz engrossa. Mostra a mão machucada, envolta num pano velho manchado.

Escuta aqui, ocê não se interessa por oração de parar sangue não? Tá vendo isso aqui, o sangue pode tá espirrando como daqui até ali, ocê bota o dedo em cima e fala as palavra: 'eu ia andando pela estrada e encontrei Nossa Senhora de Santa Eria sentada na gruta pedra fria e preguntei o que estava fazendo e ela me arrespondeu: tô benzeno e arretirano a dor dessa pessoa' e aí ocê fala o nome da pessoa. Para na hora, não fica cicatriz nem nada não!" (Renato Torto, pesquisa de campo, 1993)

Com Llansol aprendi que pensar é com o corpo e que existem muitos reais possíveis. "Quando se escreve só importa saber em que real se entra" (LLANSOL, 2011, p.14). Por que não promover um encontro entre eles, sem hierarquias, se ambos me inspiram e abrem mundos? Tenho certeza que eles adorariam se conhecer.

As palavras tem MEMÓRIA e impulsionam nossa memória. Com elas vem junto um gosto, um cheiro, uma lembrança. Denunciam de onde viemos. Meu pai, que viveu toda sua vida na roça, dizia: "vou apear do ônibus". Assim, eu via um ônibus camuflado de cavalo! E eu, menina estudada, tentava corrigir, com vergonha da ignorância do pai, apontando como errado o que de mais caro ele tinha, sua raiz com a terra, sentimento que o constituía e que ele, apesar do desconcerto que a cidade lhe provocava, trazia impresso na língua. Hoje, mulher estudada, cada vez mais consciente da minha ignorância, vejo a preciosidade desse Brasil colorido imenso, cheio de expressões riquíssimas que vão se perdendo porque esquecemos dessa memória em palavras que nos constitui e ganhamos no lugar uma língua culta, nosso português correto rede globo, cheirando azedo.

Sueli Rolnik fala que quando nos perdemos das marcas, acabamos produzindo textos sem vitalidade, que não encarnam marca alguma e isso 
ocorre quando não suportamos o estranhamento provocado justamente por essas marcas e para nos proteger nos refugiamos no oco de um conceito neutro e gratuito. (Já ouvi pesquisadores dizendo que mais chato que ler uma tese acadêmica, só bula de remédio).

E as palavras REVELAM. Não dá pra se esconder por detrás não. Um vocabulário pobre denuncia falta de leitura. (Tem que ler, não dá pra escrever bem sem ler! E ler de tudo, sem preconceito!) Palavras secas, discurso reto: falta de flexibilidade, de invenção. Palavras vagas, fugidias: em cima do muro, não quer se comprometer ou está inseguro. Palavras mascaradas: que se escondem atrás dos outros. Palavras orgulhosas: "isso é o que eu penso e pronto"! Palavras românticas: "tão lindo o que eu vivi na sala de trabalho, tão intenso, me transformou", sim e o que mais? Não dá, temos de nos expor, a palavra é sempre reveladora, então eleja o lugar de onde deseja falar e grite aos sete ventos.

Podemos nos expressar por clichês, termos seguros, fórmulas prontas, que não nos expõem, dizendo sempre do mesmo, já aceito e comprovado. Ou podemos convidar a palavra para dançar, fazer o verbo pegar delírio, como nos ensinou o poeta Manuel de Barros. Dar nascimentos a novos modos de existir, novos modos de ver.

Convidar o verbo para dançar. Sem dureza ou rigidez. Arejando espaços. Formal quando necessário, mas com respiros, espaços em branco, desvios, metáforas. Não é assim nossa criação? Por quê, quando usamos a palavra para descrever procedimentos criativos, nos tornamos, por vezes, áridos?

Devemos namorar com a palavra, sem leviandade e com um respeito desrespeitoso. Mergulhar na escrita, nas palavras, como quando exploramos ações físicas na sala de trabalho. As palavras tem som, cor, ritmo, temperatura. Também comunicam no espaço da invisibilidade, no espaço "entre", não apenas entre uma palavra e outra, mas instalando uma linha dupla entre a pessoa que escreve e a que lê. Estamos defronte a um quadro triplo e dinâmico: quem escreve, o universo aberto pelas palavras e quem a recebe. 
PALAVRA COMO CRIAÇÃO.

PALAVRA COMO RESISTÊNCIA.

PALAVRA COMO CRIADORA DE MUNDOS.

"Escrevo porque acredito no poder da narrativa da vida em transformar a própria vida. E acredito mais ainda no poder de transtornála” (BRUM, 2013, p.18).

Não ter medo do risco.

\section{Escrevo em letras gigantes:}

\section{ESCREVER É PERIGOSO!}

Não ter medo de nada encontrar, não ter medo de se vazar, de se perder ou do que vai encontrar, do vazio, da angústia, do nó na boca do estômago. Escrever não combina com o medo.

Nosso desafio é esvaziar o olhar e ampliar a escuta. A escrita já está lá, garimpar em cada processo de criação a escrita que lhe é particular. Que corpo de palavras essa experiência pede? Qual ritmo, cheiro, espaço, tempo? $\mathrm{Ou}$ quais ritmos, cheiros, espaços, tempos? Assim no plural e tudo misturado. Expandir o olhar, olhar pelo canto dos olhos, olhar de estrangeiro, de quem vê pela primeira vez. Eleger linhas sobre o que narrar e depois ir enovelando as linhas e criando uma narrativa múltipla, fragmentada, que dê conta do concreto e do sensível. Uma escrita sem hierarquias de valores, não importa a origem, se é da ordem da sensação, do concreto, do prático, do teórico, do sensível, do pensamento, do ontem, do agora, do que se intui. Tudo são pistas a serem observadas e absorvidas.

Escrever COM e não escrever sobre. "Escrever sobre é pegar num acontecimento e colocá-lo num lugar exterior a mim. Escrever com é dizer: estou com aquilo que estou a escrever" (LLANSOL, 2011, p.12). E isso implica observar sinais, atentar para os detalhes. Compõe com o vivido, não vem depois do vivido, é conatural a ele.

Perceber a diferença entre o falar de dentro (do vivido) partindo do dentro (do lugar da experiência) e o falar de fora sobre o dentro, que é a maneira que normalmente fazemos. Nos distanciando, muitas vezes 
excessivamente, da matéria originária viva e pulsante. Deixando plano e linear o que é tortuoso e multidimensional por nascimento e natureza.

O mesmo com os conceitos teóricos, necessários e bem-vindos, parceiros dessa criação. Absorvê-los e internalizá-los e não falar sobre eles, mas com eles, em atravessamento mútuo. E quem sabe novos conceitos possam surgir? Eles estão ao nosso lado para nos provocar, instigar, desafiar, inspirar e não para validar ou traduzir nossa pesquisa prática.

E a pergunta que sempre nos assombra: como eu faço tudo isso? Fazendo! Fuçando, batendo a cabeça, propondo. Não tem fórmula a ser seguida, ensinada. Não existe um lugar a se chegar. Cada processo criativo, seja na construção de uma poética cênica ou de uma escrita reflexiva é sempre um recomeço. Não tem essa de "encontrei a minha escrita". O que te diz hoje, não te diz amanhã. $O$ que serve para um processo não necessariamente vai servir a outro.

E não tem como escrever a não ser escrevendo. Exercitando esse músculo. Não desce do céu milagrosamente aquela ideia genial. É muito suor. Nunca vi nenhum escritor dizer que senta em sua escrivaninha e a escrita jorra suavemente. E nós, que nem somos escritores, a tarefa se torna ainda mais árdua. Mas temos por obrigação não banalizarmos as palavras ou reduzir nossas pesquisas sobre processos criativos a descrições de procedimentos metodológicos.

Criar estratégias. Se propor experiências. Escrever durante a madrugada, andando, no ponto de ônibus, escrever depois de ler aquele autor que te inspira. Escrever logo após o trabalho prático ou no mesmo dia ou uma semana ou um mês depois e ver quais temperaturas aparecem com o passar do tempo. Gravar. Desenhar. Fotografar. Escrever em terceira pessoa. Escrever pra alguém. Provar diferentes tipos de narrativa.

Cultivar um diário de trabalho, um caderno de artista, uma espécie de mapa do caminho, onde seja possível registrar os rastros e marcas da pesquisa em suas diferentes materialidades e temporalidades. Criar um espaço íntimo e transparente, sem censura, que depois possa ser revisitado, fornecendo diferentes pistas a serem desenvolvidas ou simplesmente como 
fonte de textos quentes que podem ser usados diretamente na narrativa final.

O Diário representa a sequência dos pontos de referência que um escritor estabelece e fixa para reconhecer-se, quando pressente a metamorfose perigosa a que está exposto. É um caminho ainda viável, uma espécie de caminho de ronda que ladeia, vigia e, por vezes, duplica o outro caminho, aquele onde errar é a tarefa sem fim (BLANCHOT in JUNQUEIRA, 1997, p.9).

E não perder de vista que RECONTAR é sempre um ato de criação, pois envolve memória e seu fluxo circular e contínuo, em constante atualização. Toda narrativa se desenvolve no tempo, fala do tempo e no tempo. Ou em outras palavras: "explicar é sempre uma reformulação da experiência que se explica (MATURANA, 2001, p.42). E essa reformulação ou recriação é intimamente ligada com quem a formula e ao momento em que a formula e explicar uma experiência é uma experiência distinta da experiência que se pretende explicar.

Então, boa sorte pra nós!

Encerro com mais um trecho da fala da Sara Elton Panamby:

Indianara Alves Siqueira, pessoa de peito e pau, puta, ativista das ruas, das políticas transvestigêneres pontua em suas falas que a escrita é uma invenção masculina e heteronormativa que carrega consigo a morte de vários saberes solapados pelas histórias oficiais. A escrita silencia. Faço aqui então uma tentativa de uma escritura que possa abrir uma escuta vozes emudecidas pelo tempo dos homens, vozes estas que fazem parte de meu limitado compêndio de experiências. Pela ideia de uma radicalidade que revele raízes esquecidas. Segundo uma ética de expropriação e terrorismo poético, sabotar as estruturas por infiltração. É como uma casa, de uma pequena infiltração pode cair o muro... Queremos derrubar a Casa Grande (PANAMBY, 2017, p.17).

$$
* * *
$$

\section{REFERÊNCIAS}

BRUM, Eliane. A Menina Quebrada e Outras Colunas de Eliane

Brum. Porto Alegre: Arquipélago Editorial, 2013.

JUNQUEIRA, Márcia Rodrigues. In: ANDRADE, Paulo e SILVA, Sérgio

Antonio (Org.). Um corp'a'screver. Belo Horizonte: FALE/UFMG, 1997. p. 8-13.

LLANSOL, Maria Gabriela. Entrevistas. Belo Horizonte: Autêntica Editora, 2011. 
MATURAnA, Humberto. Cognição, Ciência e Vida Cotidiana. Belo Horizonte: Editora UFMG, 2001.

OZ, Amós. De amor e trevas. São Paulo: Companhia das Letras, 2005.

ROLNIK, Suely. Cadernos de Subjetividade, v.1 n.2: 241-251. Núcleo de Estudos e Pesquisas da Subjetividade, Programa de Estudos Pós-Graduados de Psicologia Clínica, PUC/SP. São Paulo, set./fev. 1993.

Acesso em: 08/02/2018

<http://www4.pucsp.br/nucleodesubjetividade/Textos/SUELY/pensamentoco rpodevir.pdf>

ROLNIK, Suely. Cartografia Sentimental: transformações contemporâneas do desejo. Porto Alegre: Sulina; Editora da UFRGS, 2011.

PANAMBY, Sara Elton. Perenidades, porosidades e penetrações: [trans]versalidades pela carne. Pedregulhos pornográficos e ajuntamentos gózmicos para pesar. Eu não sabia que sangrava até o dia em que jorrei. 2017. 483fls. Tese (Doutorado em Artes) - Universidade do Estado do Rio de Janeiro, Rio de Janeiro, 2017.

UNO, Kuniichi. A Gênese de Um Corpo Desconhecido. Trad. Christine Greiner com colaboração de Ernesto Filho e Fernanda Raquel. 2. ed. São Paulo: n-1 edições, 2012.

Recebido em março de 2019.

Aprovado em abril de 2019.

Publicado em junho de 2019. 